\title{
Study of composition and properties of carbon- containing industrial rubber waste pyrolyzates
}

\author{
Evgeniya Makarevich $^{1^{*}}$, Andrey Papin $^{1}$, and Tatiana Cherkasova ${ }^{1}$ \\ ${ }^{1}$ T.F. Gorbachev Kuzbass State Technical University, 28 street Vesennyaya, Kemerovo, the Russian \\ Federation
}

\begin{abstract}
The study of mining industry rubber waste pyrolyzates and the search for new opportunities to expand the areas of their application remains an urgent research task. The study of the solid residue of industrial rubber waste pyrolysis is presented in the work. Possibilities of improving the quality characteristics of solid carbon residue are considered. The results of studying the composition by various methods are presented. The adsorption properties of the obtained product are studied and the content of oxygen-containing functional groups in the initial and the upgraded carbon residue of pyrolysis are determined.
\end{abstract}

\section{Introduction}

A huge amount of rubber-containing waste is generated during the production and after the use of all types of rubber goods, the bulk of which are worn-out car tires. Rubber waste, unlike some other waste types (wood and vegetable waste, food industry waste, etc.), is practically not subject to degradation under the influence of climatic factors and the activity of microorganisms. Therefore, significant efforts are being made to develop environmentally friendly technologies, methods and equipment for their processing in various countries.

In the annual message to the Federal Assembly, April 21, 2021, the President of the Russian Federation V.V. Putin emphasized the need to develop a mechanism for extended liability of manufacturers and importers for the disposal of goods and packaging, to provide for strict responsibility for non-compliance with environmental standards, to make funds received from environmental payments targeted and direct them to eliminate accumulated harm and improve the environment. At the same time, the volume of harmful emissions into the atmosphere should decrease by 20 percent by 2024 in 12 largest industrial centers of the country. According to the President, this task should be tackled through a comprehensive modernization of industry, housing and communal services, transport, and energy.

In the Russian Federation there is a list of goods and packaging to be processed after they have lost their consumer properties. Tires and other rubber goods are included in

\footnotetext{
* Corresponding author: evgeniyamakarevich@mail.ru
} 
this list. The recycling rate for these goods is set equal to $15 \%$ in $2016,20 \%$ - in 2017 and $2018,25 \%$ - in 2019, 30\% - in 2020 and 2021.

The landfill ban for such wastes will contribute to the development of an infrastructure for waste collection and disposal, and the utilization of existing production facilities.

At the same time, the problem of recycling worn-out automobile tires and out-of-service rubber goods is of great environmental and economic importance. The non-renewability of natural raw materials necessitate the use of secondary resources with maximum efficiency. Unfortunately, at the present time the secondary waste recycling market is not sufficiently developed to annually cope with disused tires.

With the increasing interest in waste recycling, pyrolysis can be considered as a process of obtaining commercial benefits from rubber waste, which has advantages over other methods of recycling waste tires - it is converting into marketable products, the possibility of further using rubber pyrolyzates.

Pyrolyzates are known to be used as fuel and adsorbents.

But to increase the economic efficiency and expand the areas of application of pyrolyzates, further research is needed in the field of process conditions and its optimization, as well as the study of the characteristics and methods of further processing and use of goods obtained from rubber waste pyrolyzates.

\section{Materials and methods}

The object of the research is the solid carbon residue of pyrolysis of tires of the company "KEK +" (Kaltan, the Kemerovo region, Russia)

When conducting the research, its composition was investigated. Technical and elemental analysis was carried out. Adsorption properties were studied.

Technical and elemental analysis of the solid carbon residue was carried out in accordance with the State Standards GOST R 53357-2013 and GOST R 53355-2009. The structural features of the compounds in the composition of the carbon residue were investigated by IR spectroscopy. The total specific surface area of the solid carbon residue was determined by the methylene blue adsorption method. The method described in the State Standard GOST 17219-71 was used to determine the total pore volume of the carbon residue of tire pyrolysis by the moisture capacity test. According to the State Standard GOST 4453-74, the adsorption activity of the solid carbon residue was determined using the methylene blue indicator.

The method described in the State Standard GOST 6217-74 was used to determine the adsorption activity of the carbon residue of tire pyrolysis by the adsorption of iodine. Isotherms of methylene blue adsorption on the solid carbon residue are plotted. The content of oxygen-containing functional groups in the carbon residue of pyrolysis is determined.

\section{Results and discussion}

Technical and elemental analysis of the solid carbon residue was carried out. Its composition has been studied. It was found that the carbon residue has average values of ash content (8.9-20.40\%), high values of the yield of volatiles (7.50-16.55\%) and sulfur content (3-5\%). The results of elemental analysis showed that the solid residue of pyrolysis contains about 80 wt. $\% \mathrm{C}, 1.5$ wt. $\% \mathrm{H}$

The structural features of the compounds in the composition of the carbon residue have been studied by IR spectroscopy. The infrared absorption spectrum contains bands due to stretching vibrations of carbon atoms in alkanes and alkyl fragments, stretching vibrations of $(\mathrm{C} \equiv \mathrm{C})$ group in alkynes, $(\mathrm{N}=\mathrm{C}=\mathrm{S}, \mathrm{SC} \equiv \mathrm{N})$ groups in thiocyanates. 
The absorption bands, which can correspond to $(\mathrm{C}=\mathrm{O})$ carbonyl group, $(\mathrm{C}=\mathrm{C})$ group of alicyclic compounds, $(\mathrm{C}-\mathrm{C})$ group of aromatic hydrocarbons, as well as the bands characterizing sulfur-containing compounds were also found.

To expand the area of possible application of the carbon residue, it became necessary to upgrade it due to its high toxicity and pungent odor due to the process imperfection, temperatures of the pyrolysis process, which are not high enough to intensify aromatization and polycyclization reactions.

The carbon residue was upgraded by thermal processing, as a result of which highquality raw materials for the production of adsorbents and smokeless fuel were obtained. Elemental analysis showed that the upgraded carbon residue contains $86 \mathrm{wt}$ \% C, about 1.0 wt. $\% \mathrm{H}$.

The study of the structural features of the compounds in the upgraded carbon residue by the method of IR spectroscopy was carried out. It was found that as a result of upgrading, multiple $\mathrm{C}-\mathrm{C}, \mathrm{C}-\mathrm{O}$ bonds are destroyed, organic polysulfide bonds are split, as evidenced by a decrease in the intensity and the absence of absorption bands in the the infrared spectrum ranges characteristic of these groups.

The possibility of using the upgraded carbon residue as an adsorbent was studied.

Carbon adsorbents can be obtained from various materials that contain more or less complex organic compounds capable of forming a solid carbon residue under certain conditions.

According to the type of interaction between an adsorbate and an adsorbent, physical adsorption and chemisorption are distinguished.

Physical adsorption occurs due to van der Waals interactions and occurs at active sites in the depressions of the surface. Chemical adsorption (chemisorption) is caused by the chemical interaction of adsorbent and adsorbate molecules and occurs on the surface relief projections.

Physical adsorption of organic substances from aqueous solutions is most pronounced when carbon materials are used as adsorbents, since the energy of van der Waals interaction of water molecules with carbon atoms forming the surface of carbon bodies is much less than the energy of dispersive interaction of these atoms with atoms of the carbon skeleton of organic molecules. The energy of the dispersive interaction of organic molecules with an adsorbent is especially high in cases where the carbon skeletons of adsorbent molecules have a planar structure and are characterized by a conjugated system of $\pi$-bonds, as is observed, for example, in aromatic compounds.

Two processes can occur in parallel during adsorption of solutions on the surface of the carbon residue of tire pyrolysis - the adsorption of solute molecules and the adsorption of solvent molecules.

Low-polar adsorbents, such as the carbon residue of pyrolysis, better adsorb non-polar organic compounds

Due to their hydrophobic behavior, carbon materials are the most suitable sorbents for water purification from various organic impurities, since they poorly absorb the main component - water.

The mechanism for the formation of the porous structure of the solid residue of tire pyrolysis from the carbon black pore system and interparticle pores formed during carbonization of the primary carbon black structures is substantiated in the literature.

It was found that the structure of the solid residue of pyrolysis consists of carbon crystallites and small amounts of zinc oxide, zinc sulfide, kaolin, mica, and calcium carbonate. Graphite crystallites consist of 2-3 nm long planes, which, in turn, are formed by hexagonal rings. In addition to graphite crystallites, there are from one to two thirds of amorphous carbon, as well as heteroatoms. 
During the work, adsorption isotherms were obtained, which are the main criterion for choosing adsorbents for specific processes. The type of adsorption isotherms allows obtaining information on the structure of adsorbents, the thermal effect accompanying the process, and a number of other physical, chemical and engineering characteristics of the system.

According to the type of adsorption isotherms obtained, it was found that polymolecular adsorption occurs both on the initial carbon residue of tire pyrolysis, and on the upgraded one; a strong intermolecular interaction in the sorbate substance is observed, micro- and macropores are present in the adsorbent.

The adsorption activity of the carbon material was determined by the adsorption of iodine from an aqueous solution depending on the reaction time (15, 20, 30 minutes), the size of the carbon residue pieces. Iodine is adsorbed mainly on the surface of pores with a diameter of much more than $1 \mathrm{~nm}$.

Based on the data obtained, it can be concluded that the finer the adsorbent particles and the longer its contact with the iodine solution, the higher the adsorption activity. It was found that the upgraded carbon black with a particle size of $0.2 \mathrm{~mm}$ has the best adsorption activity by the adsorption of iodine.

When studying the adsorption activity by the adsorption of iodine, the sorption process occurs over the entire surface of the adsorbent, both in macro- and micropores due to the small size of iodine molecules.

The adsorption activity of the solid carbon residue by the adsorption of methylene blue characterizes the number of macropores, since large and flat methylene blue molecules can be adsorbed predominantly on macropores.

It was found that the adsorption activity of the upgraded solid residue of tire pyrolysis according to the methylene blue indicator $(224 \mathrm{mg} / \mathrm{g})$ is higher than that of the initial one $(116 \mathrm{mg} / \mathrm{g})$ and is comparable with the adsorption activity of some activated carbon brands $(210 \mathrm{mg} / \mathrm{g})$.

The study of the surface properties of carbon materials is carried out using a number of standard techniques. The surface structure is assessed by such indicators as the content of acid and carbonyl groups, the specific surface area.

It has been found that upon upgrading, the total pore volume doubles, i.e. upgrading by thermal processing increases the specific surface area of the carbon residue.

The total specific surface area of the carbon residue of tire pyrolysis was determined by absorptiometric method using methylene blue. It was found that the specific surface area of the solid residue of tire pyrolysis is $32 \mathrm{~m} 2 / \mathrm{g}$, and after upgading by thermal processing, it increases to $48 \mathrm{~m} 2 / \mathrm{g}$.

The contents of oxygen-containing functional groups in the original and the upgraded carbon residue of pyrolysis have been determined. The content and forms of oxygen bonds must be taken into account in determining the reasons for the reactivity of structural fragments in production processes. For example, the higher the content of such forms as phenolic (alcohol) hydroxyls and ether Ar-O-Ar-type bridges in coal, the lower the temperature at which of the maximum pyrolysis rate is achieved.

The absence of carbonyl and carboxyl groups in the studied samples of the carbon residues of pyrolysis and the presence of a small amount of phenolic groups in the initial solid residue were found, which is confirmed by the result of IR spectroscopy (non-intense bands in the range of $1260-970 \mathrm{~cm}-1)$.

Treatment with hydrochloric acid, leading to the dissolution and subsequent removal of mineral salts deposited in the pores of the carbon residue, increases the number of potential adsorption sites due to the release of oxygen-containing surface functional groups. Treatment with hydrogen peroxide leads to the appearance of stabilized free radicals on the coal surface. 


\section{Conclusion}

The composition and properties of the solid carbon residue of pyrolysis of industrial rubber goods are studied in the work.

It is found that the obtained solid carbon residue has low quality characteristics, a high content of sulfur compounds; therefore, upgrading is required to expand the area of its possible application. After upgrading the solid carbon residue, the quality of the product improved, the sulfur content and the adsorption activity increased.

The composition of the initial and the upgraded carbon material was studied: elemental analysis was carried out, registration and interpretation of infrared spectra were performed. It was found that as a result of upgrading, multiple $\mathrm{C}-\mathrm{C}, \mathrm{C}-\mathrm{O}$ bonds are destroyed, and organic polysulfide bonds are split.

The adsorption activity of the carbon material is determined by the adsorption of iodine. It was found that the finer the adsorbent particles and the longer its contact with the iodine solution, the higher the adsorption activity. It was found that the upgraded carbon black with a particle size of $0.2 \mathrm{~mm}$ has the best adsorption activity.

The adsorption activity of the solid carbon residue by the adsorption of methylene blue was studied. It was found that the adsorption activity of the upgraded solid residue of tire pyrolysis is higher than that of the initial one, comparable with the adsorption activity of some activated carbon brands.

The content of oxygen-containing functional groups is determined. The absence of carbonyl and carboxyl groups in the studied samples of the carbon residues of pyrolysis, but the presence of a small amount of phenolic groups in the initial solid residue were revealed.

\section{References}

1. H.Darmstadt, Ch. Roy, S. Kakiaguine, Carbon, 32, 8, 1399 (1994)

2. J. F.Figueiredo, M. F. R. Pereira, M. M. A. Freitas, J. J. M. Órfao, Carbon, 37(9) 1379 (1999)

3. M. A. Hourieh, M. N. Alaya, A. M. Youssef, Adsorption science \& technology, 15 (6), 419 (1997)

4. M. Juma, Z. Koreňová, J. Markoš, J. Annus, L'. Jelemenský, Pyrolysis and combustion of scrap tire Institute of Chemical and Environmental Engineering, Faculty of Chemical and Food Technology (Slovak University of Technology, Radlinského 9, 2006)

5. V. P. Santos, M. F. R. Pereira, P. C. C. Faria, J. J. M. Órfao, Decolourisation of dye solutions by oxidation with $\mathrm{H} 2 \mathrm{O} 2$ in the presence of modified activated carbons, J. Hazard. Mater, 162 (2-3) 736 (2009)

6. Wan Mohd Ashri Wan Daud, A.H. Houshamnd, J. Nat. Gas Chem., 12(3), 267 (2010)

7. A. Rey, M. Faraldos, A. Bahamonde, J. A. Casas et al., Ind. Eng. Chem. Res., 47, $8166(2008)$

8. L. J. Lemus-Yegres, I. Such-Basáñez, M. C. Román-Martínez, C. Salinas-Martínez de Lecea, Appl. Catal., 331, 26 (2007)

9. N. V. Beck, Meech S.E., Norman P.R., Pears L.A., Carbon, 40, 531 (2002)

10. Q. Huo, Y. Gong, T. DouEnergy\&Fuels, 24(7), 3764 (2010) 